\title{
Pyrexia of unknown origin, the age-old dilemma
}

\author{
P Deshpande, T Brammah, H Rakicka
}

A 74-year-old man presented with high-grade intermittent fever with rigors for 7 days. In his medical history there were no significant systemic illnesses. He was a non-smoker and not on any medication at the time of admission. On examination he was pale, pyrexial at $38^{\circ} \mathrm{C}$, pulse rate 84 beats/min, blood pressure $100 / 60 \mathrm{mmHg}$; he had no lymphadenopathy or hepatosplenomegaly. His systemic examination was normal.

Initial investigation revealed normocytic normochromic anaemia and thrombocytopenia. Liver function tests, blood and urine cultures were normal. Chest X-ray did not reveal any abnormality. Platelets were $70 \times 10^{9} / 1$; haemoglobin $99 \mathrm{~g} / \mathrm{dl}$; white cell count $8.4 \times 10^{9} / \mathrm{l}$; erythrocyte sedimentation rate (ESR) was $12 \mathrm{~mm}$ after one hour. C-Reactive protein was $130 \mathrm{mg} / \mathrm{l}$. Rheumatoid factor was negative. He had spikes of high fever daily. A search for any hidden abscesses using ultrasound and computed tomography of the abdomen, was unproductive. Echocardiogram did not reveal any vegetations. He was diagnosed as a case of pyrexia of unknown origin (PUO).

He was treated with a course of antibiotics, empirically, which showed no effect on his fever. His anaemia was worsening, but there was no evidence of haemolysis. He was transfused. He continued to have a high fever so a repeat thorough physical examination was performed but there were no new signs. A dental check did not reveal any tooth abscesses. Auto-antibody screening tests (antinuclear antibodies (ANA), ANCA, anti-ENA, anti-Sm, anti-DNA ss/ds) were all negative. Bone marrow examination showed dyserythropoiesis; there were no blasts. ${ }^{1}$ Tests performed to detect any underlying malignancy (eg, CEA, serum electrophoresis) were inconclusive. Antiplatelet antibodies were absent.

After 4 weeks of intense investigations, the only significant results were normochromic normocytic anaemia with thrombocytopenia and a high ESR. He continued to have fever with no fresh signs or symptoms until he noticed a rash over his legs (figure 1 ). ${ }^{23}$

Department of Medicine, Tameside General Hospital, Ashton under Lyne, UK

P Deshpande

T Brammah

H Rakicka

Accepted 23 April 1998

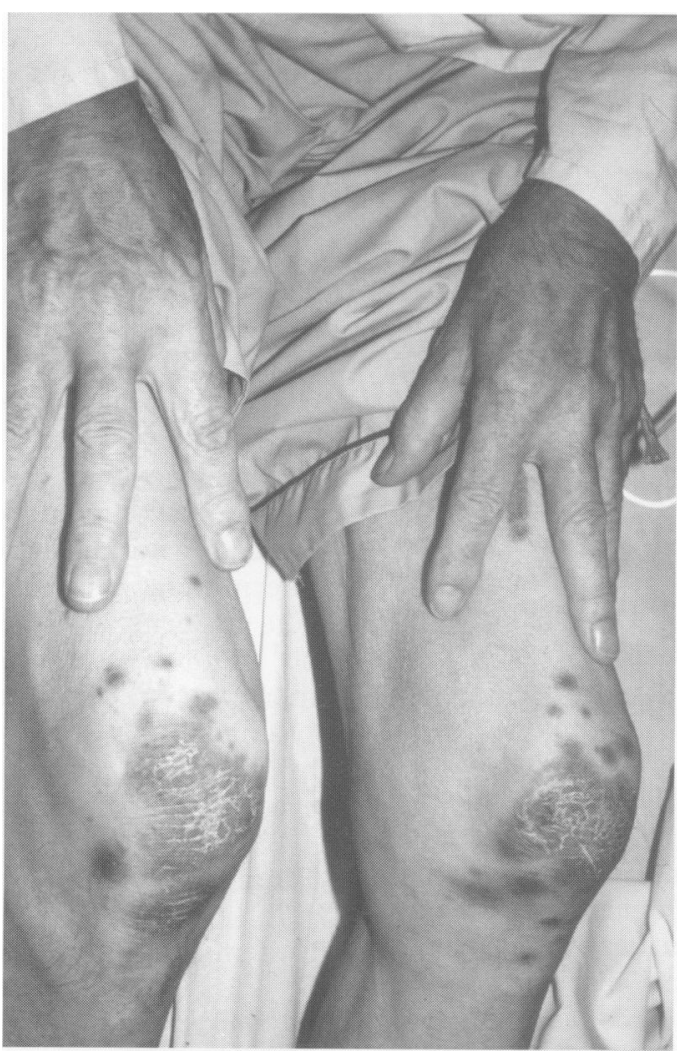

\section{Questions}

1 What is the significance of the rash shown in figure 1?

2 What other investigations should be performed?

3 How would you manage this patient? 


\section{Answers}

QUESTION 1

The rash seen on both legs is vasculitis; it is maculopapular in type, erythematous and nonitching. It suggests a connective tissue disorder. A renewed effort should be made to search for the underlying connective tissue disease. Since the illness is in a subacute stage it is worth repeating the auto-antibody screening tests, which were initially negative.

QUESTION 2

Apart from the auto-antibody screen, a repeat bone marrow aspiration plus trephine biopsy should be done since the first one showed dyserythropoiesis. Haematological malignancies are known to present as PUO and need to be firmly ruled out. The importance of repeated clinical examinations to search for new physical signs cannot be overemphasised.

QUESTION 3

The management at this stage would be symptomatic relief. There is a good argument for empirical antibiotics to be tried. Since the finger of suspicion points towards connective tissue disease, which are known to present as PUO, a trial of steroids could be given.

\section{Outcome}

The patient was started with oral steroids which resulted in a subsidence of his fever and some subjective improvement. Six weeks later, the fever re-appeared, associated with erythematous butterfly rash over the face (figure 2). ${ }^{3}$ Skin biopsy revealed lymphocytic vasculitis. His auto-antibody screening was repeated; this time anti-DNA antibody was positive, IgG antibodies were at a titre of $20 \mathrm{units} / \mathrm{ml}$ and IgM at a titre $<10$ units $/ \mathrm{ml}$. All these findings suggested systemic lupus erythematosus. ${ }^{4}$

His steroids were increased which briefly improved his platelet count from 30 to $50 \times$ $10 \%$. After an initial response to oral prednisolone, his haemoglobin and platelet levels started falling. Azathioprine was added but he continued to deteriorate. A trial of methyl prednisolone failed to bring any improvement, although his rash started to fade. His bone marrow examination was repeated which revealed myelodysplasia. ${ }^{5}$ His further course was rapidly downhill and he died.

\section{Discussion}

This case, presenting as PUO, eluded diagnosis for 6 weeks, despite all investigations. Although PUO is a known presenting feature, being a male and lacking serological evidence, the diagnosis of systemic lupus erythematosus was not reached until a typical vasculitic rash and later a malar rash appeared and anti-DNA antibody was positive.

\footnotetext{
1 List AF, Garewal HS, Sandberg AA. Myelodysplastic
} syndromes: a review. $\mathcal{f}$ Clin Oncol 1990;8:1424-41.

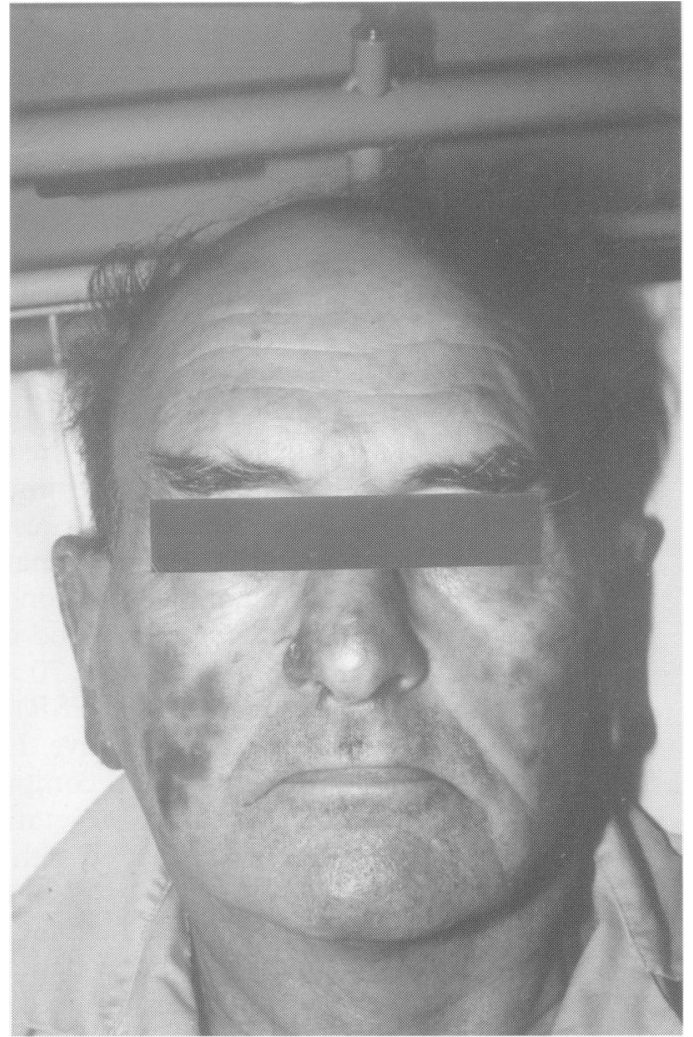

Figure 2

The detection of ANA has been a cornerstone of the evaluation and diagnosis of systemic lupus erythematosus; antibodies may be pathogenetic agents or harmless footprints of an aetiologic agent. ${ }^{6}$ The specificity of the ANA test declines with elderly patients and there are significant limitations when clinical features of systemic lupus erythematosus are equivocal or missing. ${ }^{7}$

The thrombocytopenia in this patient was not of auto-immune aetiology because antiplatelet antibodies were not detected. Therapy may not be necessary for thrombocytopenia in patients with no evidence of systemic lupus erythematosus activity in other organs or a platelet count of more than $20 \times$ $10^{9} / 1$ and no evidence of existing coagulopathy.

Glucocorticoid (prednisolone $1 \mathrm{mg} / \mathrm{kg}$ ) is usually recommended as initial treatment. Patients who fail or relapse may benefit from intermittent pulses of methyl prednisolone. The majority of patients with myelodysplasia do not benefit from intensive cytotoxic therapy. ${ }^{1}$ In our patient, the treatment of systemic lupus erythematosus was complicated by associated myelodysplastic syndrome, the eventual outcome being decided by the latter.

\section{Final diagnosis}

Systemic lupus erythematosus.

Keywords: systemic lupus erythematosus; pyrexia of unknown origin

\footnotetext{
2 Jennette JC, Falk RJ, Andrassy K, et al. Nomenclature of
} systemic vasculitides. Arthritis Rheum 1994;37:87-92. 
3 Choy EHS, Erhardt CC, Scott D, Lockwood M. Progress in vasculitis. $千$ Soc Med Sect Rheumatol Rehabil 1995;89:526-9. 4 Kanda N, Tsuchida T, Watanabe T, Tamaki K. Clinical feaKanda N, Tsuchida T, Watanabe T, Tamaki K. Clinical fea-
tures of systemic lupus erythematosis in men - characteristures of systemic lupus erythematosis in men - characteristics of

5 Bennett JM, Catovsky D, Daniel MT, et al. Proposals for the classification of the myelodysplastic syndromes. $\mathrm{Br} \mathscr{J}$ Haematol 1982;51:189-99.
6 Boumpas DT, Fessler BJ, Austin III HJ, Balow JE, Klippel $\mathrm{JH}$, Lockshin MD. Systemic lupus erythematosis: emerging concepts. Part 2: Dermatologic and joint disease, the antiphospholipid antibody syndrome, pregnancy, hormonal therapy, morbidity and mortality and pathogenesis. Ann Intern Med 1995;123:42-53.

7 Slater CA, Davis RB, Schmerling RH. Antinuclear antibody testing - a study of clinical utility. Arch Intern Med 1996;156: 1421-5.

\title{
A penile mass
}

\author{
Gamal Abd-El Monem Siam, Anthony A Hooper
}

A 67-year-old man was referred in April 1997 with dysuria. He had noticed a mass in the base of his penis (figure) since November 1996. The patient had had squamous cell carcinoma of the lung diagnosed in October 1996 and was treated by radiotherapy only. He also underwent Dormia basket extraction of a left ureteric calculus in early 1995. On presentation, he looked unwell, dehydrated, cachetic and he had exertional dyspnoea with productive cough. On his right temple he had a $3 \mathrm{~cm}$ skin lesion, clinically thought to be a metastasis but not investigated. Abdominal examination showed no intra-abdominal masses. FNA cytology of the penile mass showed groups of squamous epithelium which were highly suspicious of malignancy. Flexible cystoscopy showed that the mass was not encroaching on the urethra. There was no bladder lesion and the dysuria was relieved by increased fluid intake. The patient refused radiotherapy. He discharged himself and died 8 weeks later.

\section{Department of General Surgery, St Andrews Hospital, Devas Street, London E3 3NT, UK \\ G A-E M Siam A A Hooper}

Accepted 10 March 1998

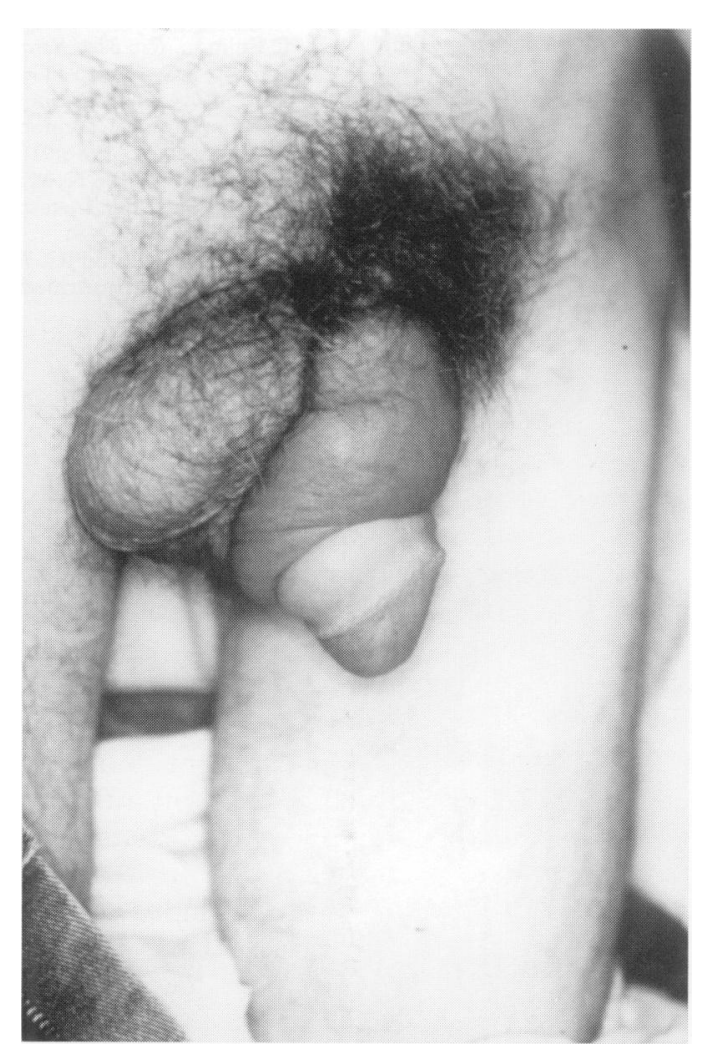

\section{Questions}

1 What can be seen in the figure?

2 What is the prognosis of this condition? 